\title{
Medical schools addressing student anxiety, burnout and depression
}

\author{
n Cite as: CMAJ 2017 December 18;189:E1569-70. doi: 10.1503/cmaj.109-5516
}

Posted on cmajnews.com on Nov. 28, 2017.

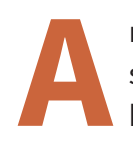

round $37 \%$ of Canadian medical students meet the criteria for burnout, according to a Canadian Federation of Medical Students (CFMS) survey sent to medical students across the country. (Preliminary data have been shared at conferences; publication expected in 2018.) In research published last year by the Journal of the American Medical Association, based on an international survey, $27 \%$ of medical students reported symptoms of depression.

Medical students are selected based on their well-roundedness, empathy and academics. But the expectation to achieve top grades has increased, according to Dr. David Muller, dean of medical education at the Icahn School of Medicine at Mount Sinai in New York. "We want our students to show love and compassion for patients, and meanwhile get 99\%. There's hypocrisy on our part as medical educators."

Another problem is that students training to care for the mental and physical health of others don't have time to tend to their own health. "You have to learn and do so much in a short period of time," said Wesley Verbeek, a medical student at the University of Alberta, and one of his program's five mental health advocates. "There's a lot of pressure to keep going, keep going, keep going, because the more you can continue the status quo, the more likely you are to get matched to the residency you want."

Medical students tend to be high-functioning and highly resilient, but the accumulation of many stressors leads to anxiety, depression and burnout, according to Dr. Franco Rizzuti, past-president of CFMS. Time-crunch pressure, lack of sleep, 70-hour weeks during clinical rota-

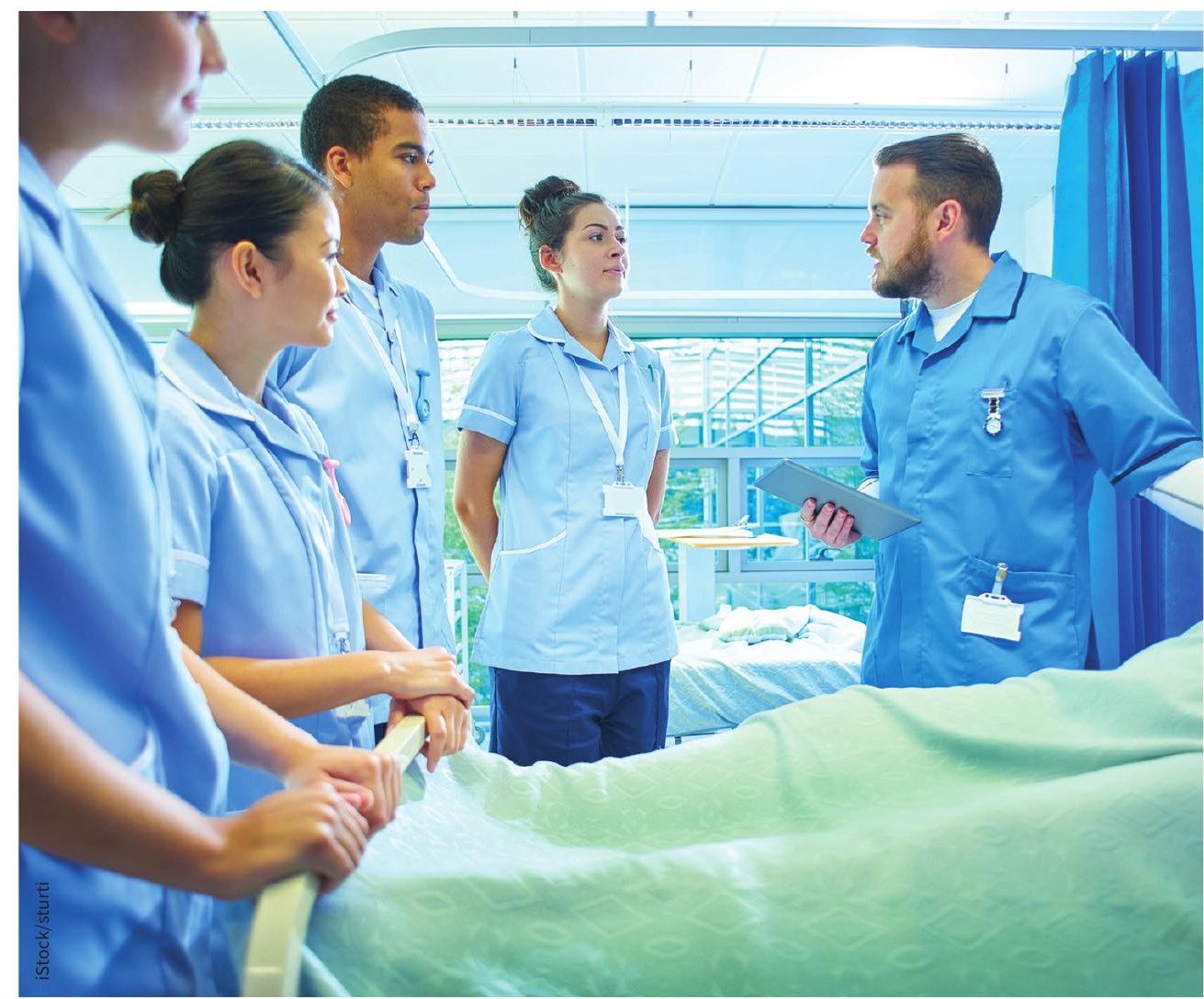

Long hours during clinical rotations, and other stressors, can lead to mental health issues for medical students.

tions, witnessing patient death for the first time, personal issues - it adds up and "even the best coping mechanisms can start to fail," said Rizzuti.

After the suicide of a medical student at Icahn in 2016, a taskforce of more than 30 faculty and students was created to develop a mental health strategy. Numerous changes were made, including the creation of awards to recognize nonacademic accomplishments, like serving the community. The grade distribution was also changed, increasing the percentage of third- and fourth-year students desig- nated with "honours" from $25 \%$ to $40 \%$. "Medical schools all pretend to know how to separate the really excellent from the just sort of excellent, but they don't," said Muller. Another change is that all medical students will have a yearly "mental health check-in" with a social worker. "In order to completely destigmatize seeking mental health support, we decided to treat it like a primary care visit," said Muller.

At the University of Alberta, medical students are launching a podcast on mental health so students and doctors can share their own experiences with depres- 
sion and anxiety. "We want to send the message to students that if they're struggling, they're not struggling alone," said Lucy $\mathrm{Ni}$, a medical student and mental health advocate.

At the medical school's annual "mental health monologues" event, students are invited to talk about their insecurities and anxieties in person. The event sets the tone for the rest of the year, said Verbeek. "When you see people crying and being real about themselves, it makes it so much easier to - later, when you're having a bad day - turn to the person beside you."

For its part, CFMS is conducting research to identify the gaps and shortcomings in mental health supports for medical students. The organization is also working with the Canadian Mental Health Association and the Canadian military to develop resiliency training for medical students, similar to the curriculum recently developed by Resident Doctors of Canada.
With burnout among residents and staff physicians estimated at $50 \%$ or above, the emotional struggles of medical students represent "the beginning of the pipeline," said Rizutti. "How are we going to improve overall health and wellness in the general physician population if our trainees - without the stress of running a business, without some of the on-call requirements - have high levels of burnout and depression?"

Wendy Glauser, Toronto, Ont. 